\title{
ESTRUTURA E CONDUTA DO MERCADO VAREJISTA DE MADEIRA SERRADA EM RIO BRANCO-ACRE
}

\author{
Zenóbio Abel Gouvêa Perelli da Gama e Silva ${ }^{1}$, Ívina Zuleide Gonçalves de Sousa ${ }^{2}$ \\ Eng. Florestal, Dr., Depto. de Ciências Agrárias, UFAC, Rio Branco, Acre, Brasil - zenobiosilva@ hotmail.com \\ Enga ${ }^{a}$ Florestal, Conselho Nacional dos Seringueiros, Rio Branco, Acre, Brasil - ivina_sousa@ hotmail.com
}

Recebido para publicação: 15/05/2008 - Aceito para publicação: 25/09/2009

\begin{abstract}
Resumo
Este artigo objetiva gerar informações econômicas sobre o mercado madeireiro varejista de Rio Branco (AC), no período 2005-6. Com dados levantados nas 27 revendas locais de madeira, fez-se uma análise estrutural, enfocando a estrutura e conduta desse mercado. Na estrutura, abordaram-se, nesse mercado, os graus de concentração e de diferenciação dos produtos, e na conduta, avaliaram-se as políticas de preço e de promoção. Dos resultados obtidos, concluiu-se que: (1) esse mercado era um oligopólio, altamente competitivo na venda de madeira; (2) todas as firmas ofereciam garantia da qualidade, pronta-entrega e frete grátis dos produtos; assim, tais serviços não diferenciavam a madeira comercializada nessas empresas; (3) a maioria dos depósitos estabelecia o preço de venda considerando custo de comercialização mais uma margem de lucro; (4) a lista telefônica era o principal meio de propaganda usado por essas firmas; (5) nesse mercado, adotava-se muito o desconto no preço à vista e a demonstração do produto aos compradores; e (6) difundir informações e distribuir brindes ou doações eram ações pouco ou mesmo não adotadas nesse mercado.

Palavras-chave: Madeira serrada; formação de mercado; estrutura de mercado; índices de concentração.
\end{abstract}

\begin{abstract}
Structure and behavior of lumber retail market in Rio Branco, Acre-Brazil. This article aimed to generate information on the market of sawtimber, at retail level, in Rio Branco-AC, during 2005-2006 period. Using data from 27 lumber retailers, it was carried out a structural analysis, focusing structure and conduct of this market. In structure terms, they were approached concentration and product differentiation degrees, and in conduct they were evaluated policies related to pricing and promotion played in this market. The results obtained made it possible the following conclusions: (1) The market surveyed was oligopoly, highly competitive in the sale of its product; (2) All enterprises provided guarantee of quality, prompt delivery and free freight of their commodity for their consumers, so, these services did not differentiate the product sold by these firms; (3) Most of the enterprises establish the price of their commodity taking into account the commercialization costs plus a profit margin; (4) The telephonic list was the propaganda media more used by the analyzed firms; (5) Offering discounts for sale in cash and demonstration of products for their clients are procedures very adopted in this market and (6) Distribution of gifts, donations and to make public information about their lumber were action played by a few number or even by no one of local timber retailers.
\end{abstract}

Keywords: Sawtimber; market formation; market structure; concentration index.

\section{INTRODUÇÃO}

A sociedade mundial, conscientizada sobre a necessidade da conservação do meio ambiente para a sobrevivência da humanidade, vem demandando, dos setores que têm a floresta como a fonte da sua matéria-prima, ações voltadas ao uso racional desses recursos naturais.

Essa realidade tem um impacto significativo para a Amazônia brasileira, pois, segundo a ABIMCI (2007), essa região, além de responder por $85 \%$ da produção brasileira de madeira nativa, abriga a maior floresta tropical do mundo. Portanto, o Brasil é um país-chave nas discussões sobre o aproveitamento dos recursos florestais e sobre o reflexo desse aproveitamento na conservação do meio ambiente. 
Diante desse cenário, o estado do Acre merece, também, destaque nos debates sobre o tema ambiental. Tal situação se deve ao fato de que, conforme Acre (2006), da área total desse Estado $\left(165.150 \mathrm{~km}^{2}\right), 87,4 \%$ contam, ainda, com a sua floresta nativa de forma intacta, a qual, se explorada adequadamente, poderá gerar emprego e distribuição de renda para a população local, sem, contudo, comprometer o futuro desse bioma.

Todavia, cabe aqui enfatizar que, para o desenvolvimento pleno e duradouro dessa região, baseado no uso do seu potencial florestal, este processo produtivo deve estar em sintonia com uma política pública que fomente o aproveitamento, num nível sustentado, desses recursos naturais.

Dessa forma, quando da elaboração de diretrizes governamentais, voltadas a orientar o emprego mais apropriado, sob os aspectos técnicos, econômicos e sociais, das florestas acreanas, é válido levar em conta as palavras de Sills; Abt (2003), os quais argumentam que a formulação de tais políticas pode ganhar muito com as informações geradas nos estudos de mercado. Com isso, os resultados dessas pesquisas têm potencial de se tornarem importantes subsídios para se analisar como os produtores e consumidores estão valorizando os bens florestais e como está sendo a extração, a industrialização e a comercialização desses produtos.

Aliado a esse fato, tem-se que, ao se visar a exploração racional dos recursos florestais, é necessário ter em mente a relação que a floresta possui com o conceito de demanda derivada, na cadeia produtiva madeireira, como aponta Klemperer (1996). Assim, para a efetivação do manejo florestal, devese, inicialmente, transformar o consumidor num agente que valoriza mais o produto madeireiro, o que o deixaria disposto a pagar um valor maior por essa mercadoria. $\mathrm{O}$ fornecedor dessa madeira, o dono de um depósito, por sua vez, com a elevação da sua receita, poderia aceitar um preço maior por sua matériaprima, cobrado pela serraria que o abastece. Já o industrial madeireiro, com um preço melhor para o seu produto, teria condições de arcar com o custo incremental, no seu processo produtivo, advindo da alteração da origem da sua matéria-prima, da exploração convencional em áreas de conversão para o manejo florestal sustentável. Com isso, fechar-se-ia o ciclo, em que um consumidor bem atendido pelo mercado, na oferta do seu produto madeireiro, fomentaria, em última análise, a realização do manejo florestal numa determinada região. Complementando, essa sequência a que a madeira obedece entre a floresta e o seu consumidor final vem mostrar a importância de se conhecer o mercado e de torná-lo adequado para viabilizar o aproveitamento racional desses recursos naturais, e que, para tal, há também a necessidade de políticas que promovam tais processos mercadológicos e produtivos.

Agregando informações a essa premissa sobre a utilidade dos estudos de mercado na elaboração de políticas públicas, Stead et al. (1996) e Hasenclever; Kupfer (2002) apontam a adoção da análise estrutural do mercado como apropriada para embasar a formulação de diretrizes governamentais, pois consideram que essa abordagem indica os meios que tornam melhor o desempenho da economia.

Nesse contexto, tem-se que a análise estrutural, de acordo com Cramer; Jensen (1991), visa enfatizar a natureza da competição no mercado. E, para alcançar esse objetivo, Clarke (1994), Mendes (1994), Stead et al. (1996), Cabral (1998) e Hasenclever; Kupfer (2002) listam a estrutura, a conduta e o desempenho do mercado como os conceitos-chave que embasam os estudos nessa área.

Detalhando ainda mais a abordagem estrutural do mercado, Magrath (1992) e Duerr (1993) salientam que a estrutura do mercado influencia a conduta dos integrantes desse mercado, e esta, por sua vez, gera impactos no desempenho da economia do país. Assim sendo, Cabral (1998) sintetiza, na figura 1, as relações que a estrutura, a conduta e o desempenho do mercado têm entre si, assim como a afinidade dessas variáveis com as políticas públicas.

Como indicado na figura 1, a atuação da estrutura, conduta e desempenho do mercado tanto reflete nas diretrizes governamentais quanto está sujeita aos impactos das políticas públicas. Entre os instrumentos e medidas de políticas públicas que apresentam ligação direta com o mercado, Carlton; Perloff (1994) relacionam: 1) políticas regulatórias de mercado, em que se destacam aquelas com finalidades antitrustes ou as que criam ou eliminam barreiras à entrada e saída de firmas no mercado; e 2) taxas, subsídios e incentivos para investimentos e criação de empregos, assim como políticas macroeconômicas.

No que se refere à estrutura do mercado, segundo Mendes (1989, 1994 e 1998), Stead et al. (1996) e Cabral (1998), ela enfoca os graus de concentração entre os membros desse mercado, de diferenciação dos produtos, bem como de barreiras à entrada e/ou saída de um integrante no mercado em questão. 
Quanto ao grau de concentração, Labini (1984) e Kon (1994) mencionam que esse pode ser avaliado em função da participação que as firmas têm na venda total, na geração de emprego e na propriedade de ativos numa indústria. Assim sendo, Resende; Boff (2002) relatam que, conhecendo a parcela de cada empresa do mercado, o grau de concentração visa revelar o quanto é dominante o comportamento dessas firmas no mercado em análise. Já Caves (1982), Gregory (1987), Mendes (1989 e 1994) e Marques; Aguiar (1993) apresentam critérios e métodos que permitem, fazendo-se uso dos valores da concentração, obtidos numa análise sobre um determinado mercado, identificar a estrutura a que este pertence.
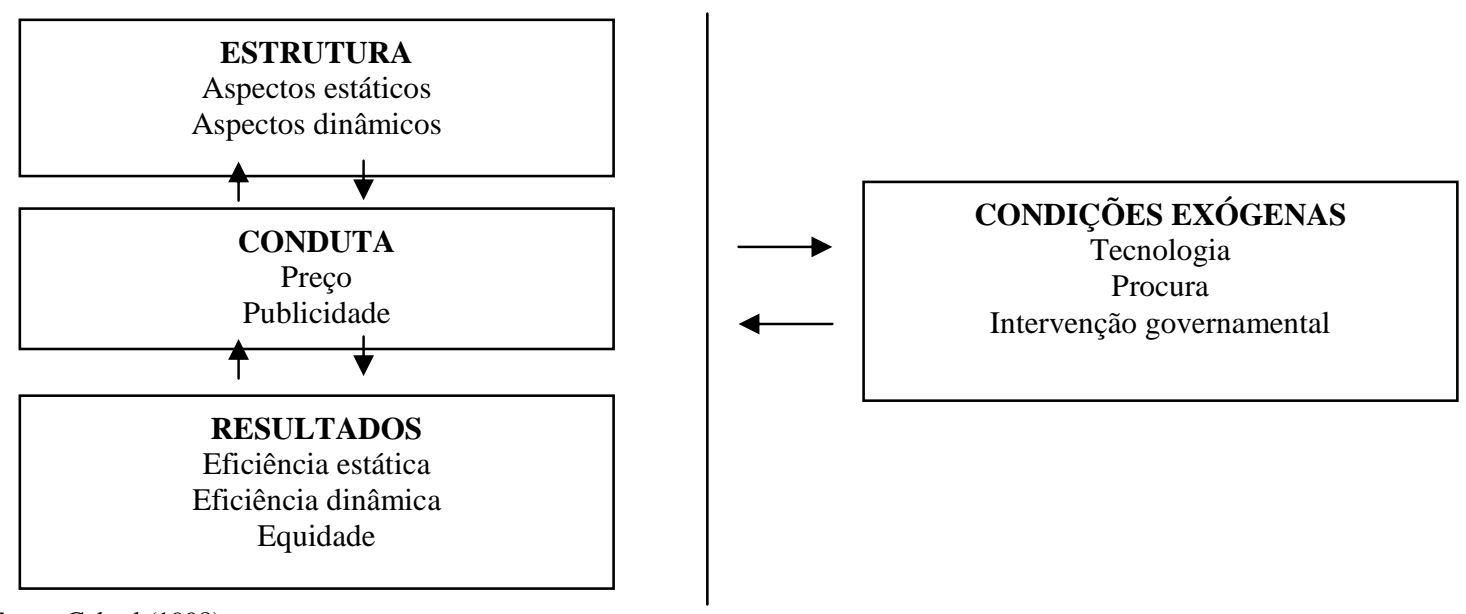

Fonte: Cabral (1998).

Figura 1. Elementos da organização de mercado.

Figure 1. Elements of market organization.

Ao se relacionar a identificação da estrutura de um mercado com a atividade florestal, são relevantes os comentários de Murray; Prestemon (2003). Esses autores defendem que, ao se avaliar a estrutura do mercado no qual uma firma atua, os elaboradores de políticas devem se preocupar com o custo social gerado pela competição imperfeita no mercado madeireiro, como também com a habilidade do mercado abordado em guiar a sociedade para a alocação ótima dos fatores de produção florestal.

Complementando, é importante salientar que o setor florestal tem sido alvo de vários estudos que pesquisam a estrutura do mercado de seus produtos. Entre os trabalhos publicados sobre esse tema, podese indicar Nautiyal et al. (1985) e Silva et al. (1992), os quais enfocaram o mercado de produtos florestais no Canadá e no Brasil, respectivamente, enquanto Noce et al. (2005) abordaram a concentração das exportações mundiais de madeira serrada. Quanto às pesquisas abordando a produção de bens usando madeira tropical, tem-se Santos; Santana (2003), estudando a participação das firmas na elaboração de artefatos de madeira no estado do Pará, e Silva (2003), analisando a concentração no uso da madeira tropical pelas marcenarias acreanas, entre outros.

Conceituando o grau de diferenciação de um bem entre a oferta de vários fornecedores, Braga (1980) afirma que esse grau mostra o quanto tal mercadoria é tida como homogênea pelos compradores. Complementando, Mendes (1989) cita que, diferenciando seus produtos, a firma pode ter incentivos para: 1) investir em propaganda e promoção; 2) ajustar os custos de produção às condições de demanda; e 3) variar a apresentação e qualidade do produto.

Cabe aqui mencionar Haveman; Knopf (1972), os quais argumentam que, no oligopólio, o produto não precisa ser homogêneo, como na concorrência perfeita ou monopólio. Silva; Luiz (1995) acrescentam que, mesmo os bens produzidos num oligopólio sendo perfeitamente substituíveis entre si, eles são diferenciados, o que permite ao consumidor conhecer o produtor que forneceu tal produto.

Com respeito à análise da conduta do mercado, de acordo com Bain (1956), esta avalia o comportamento padrão que as firmas adotam para se adaptar ou se ajustar ao mercado em que atuam. No caso específico de um oligopólio, Clarke (1994) comenta que cada firma reconhece que o seu sucesso depende dos seus atos, como também das ações dos seus concorrentes. 
Nesse contexto, Steele et al. (1971), Mendes (1994) e Cabral (1998) relatam que a análise da conduta do mercado leva em conta temas como: 1) políticas de preços;2) planificação e aperfeiçoamento do produto; 3) políticas de promoção; e 4) reações quanto às políticas de preços e de promoção praticadas pelos concorrentes.

Entre as políticas de preço a serem identificadas e avaliadas na conduta do mercado, tem-se a situação, indicada por Cramer; Jensen (1991), em que se espera que as firmas formadoras de preços (podendo fixar seus preços, quantificar a sua produção ou, pela sua força de mercado, enfraquecer ou eliminar seus competidores) atuem diferentemente das firmas tomadoras de preços. Outra forma de política de preço a considerar no estudo da conduta do mercado é o caso, revelado por Stead et al. (1996), em que as empresas, para segmentar mercado, possibilitam preços-prêmios para alguns grupos de clientes e oferecem descontos para outros.

Braga (1980) enfatiza que, no oligopólio, pelo tamanho de cada firma, os ajustes de posição por elas realizados podem influenciar os preços ou os volumes de vendas das outras firmas da indústria (a necessidade de se antecipar à reação dos concorrentes torna mais complexo o processo sobre a decisão preço-produção). Já Mendes (1994) salienta que as firmas, no oligopólio, para manter condições estáveis no mercado, buscam evitar competição de preço. Em situações como essa, tem-se uma interdependência entre tais empresas, o que possibilita o estabelecimento de: 1) acordos entre as firmas (em termos de fixação de preço e divisão de território ou área de mercado); 2) liderança de preço; e 3) conluio.

Também com relação à formação de preço, Varian (1997) cita que num oligopólio pode haver a firma líder (que fixa, antes das outras firmas, o seu preço, ou nível de produção) e as firmas seguidoras (que adotam o preço ou o nível de produção fixado pela empresa líder).

Complementando, Hall; Hitch (1939) concluíram, ao estudarem firmas do setor industrial, que elas não agem visando maximizar seu lucro, mediante a busca por operar no nível de produção em que a sua renda marginal é igual ao seu custo marginal, como argumenta a teoria econômica marginalista. Formulando o princípio do custo total, esses autores apontam que essas empresas têm, como decisão principal, determinar o preço $(P)$ e não a quantidade, como preconiza a microeconomia tradicional. Assim, o preço é fixado por meio de uma margem fixa ("mark-up") que incide sobre o custo variável médio (CVme), como indicado na seguinte expressão:

$$
P=\text { CVme . }(1+\text { mark }-u p)
$$

As políticas de promoção de vendas, por sua vez, como propõe Kotler (1994), abordam: 1) publicidade ou propaganda; 2) promoção de venda propriamente dita; 3) relações públicas; e 4) venda pessoal.

Pelo exposto, são oportunas pesquisas que enfoquem, economicamente, o setor florestal acreano. Cabe ressaltar que Silva $(2000,2004,2005$ e 2007) abordou a produção e comercialização de produtos madeireiros no Acre, nos anos de 1996, 2002, 2004 e 2005. Porém, é válida uma continuidade nas avaliações sobre o comportamento do mercado desses bens ao longo dos anos, as quais podem correlacionar as estruturas de mercado identificadas, em cada ano analisado, com as políticas públicas para esse setor produtivo no referido período.

Assim, justificam-se trabalhos que analisem os reflexos, para o setor acreano de madeira serrada, das diretrizes governamentais, implementadas no período 1999-2006, que, entre outros pontos, capacitaram as firmas madeireiras regionais na prática do manejo florestal, minimizaram os trâmites burocráticos para a aprovação dos planos de manejo florestal e buscaram mercado para o produto madeireiro local, oriundo de áreas manejadas.

Considerando, então, a relevância de se conhecer o mercado de bens florestais para o desenvolvimento do estado do Acre, este estudo objetiva gerar informações econômicas sobre a comercialização de madeira serrada em 2005-6, em Rio Branco, capital do estado. Em termos específicos, esta pesquisa visou analisar o mercado madeireiro, em nível varejista e em atividade nessa capital, no período em questão, quanto aos aspectos da sua estrutura e da conduta das firmas que dele fazem parte.

\section{MATERIAL E MÉTODOS}

\section{Material}

Área de estudo

O local adotado para a realização desse estudo foi o município de Rio Branco. Mais especificamente, a população-alvo desta pesquisa foi o grupo dos depósitos instalados nesse município que comercializaram madeira tropical serrada no período de 2005-6. 
A escolha da capital Rio Branco para a coleta de dados desta pesquisa se deve à importância que ela tem para a economia florestal local. Mais especificamente, de acordo com Acre (2006), Rio Branco é o principal município da Regional do Baixo Acre (da qual fazem parte, também, os municípios Acrelândia, Bujari, Capixaba, Porto Acre, Plácido de Castro e Senador Guiomard), a qual responde por $66 \%$ da produção madeireira acreana e $63 \%$ do parque industrial madeireiro estadual, cujas firmas se concentram nessa capital.

\section{Dados primários}

Os dados primários empregados nesta análise foram sintetizados nos seguintes itens: 1) volume de madeira comercializado; 2) políticas de preço; 3) práticas de promoção de vendas e oferecimento de serviços especiais; e 4) políticas de relacionamento com os clientes e concorrentes.

Cabe aqui mencionar que, para se obter tais dados, foram entrevistados pessoalmente, no mês de agosto de 2006, e com o uso de formulário específico, todos os vinte e sete membros atuantes no setor varejista de madeira serrada de Rio Branco nessa data. Segundo Sproull (1988) e Gil (1995), essa técnica, entrevista face a face, é a mais indicada num levantamento desse gênero, para gerar um maior aprofundamento nas respostas. Salienta-se que, nessa mesma ocasião, os empresários amostrados forneceram os dados, mencionados anteriormente, referentes aos anos de 2005-6.

Nesse levantamento, para se testar o formulário aplicado neste estudo, foi realizada, também, uma amostragem-piloto com algumas firmas escolhidas, aleatoriamente, na população dos depósitos em atividade no mercado em questão. Tal procedimento foi adotado porque, como argumenta Sproull (1988), ele permite a geração de informações num nível de confiabilidade e consistência desejado e a formulação de perguntas que gerem uma perfeita interpretação (pelos entrevistados) dos temas levantados.

É válido enfatizar que a análise das respostas obtidas nessa amostragem-piloto revelou que as perguntas, como foram elaboradas, permitiam que os entrevistados tivessem uma perfeita interpretação dos pontos abordados, gerando, assim, informações com o padrão de qualidade esperado. Diante dessa constatação, esse formulário não sofreu alteração, continuando a ser aplicado nas demais entrevistadas deste estudo, assim como os dados coletados nesse levantamento preliminar mereceram ser incluídos no processamento definitivo desta pesquisa.

Dados secundários

Como dados secundários para esta pesquisa, foram usadas as informações, geradas por Silva (2000), sobre o perfil do mercado madeireiro identificado em Rio Branco em 1996. Saliente-se que tais dados enfocam a comercialização de madeira serrada nos depósitos dessa capital considerando níveis de concentração e de prestação de serviços especiais (garantia da qualidade, pronta-entrega e frete grátis do produto comercializado), assim como a conduta das firmas (quanto às políticas de preço, de promoção de venda e de relações pública) nesse mercado.

É importante destacar que o uso das informações apresentadas no estudo de Silva (2000) possibilitou uma avaliação do mercado de madeira serrada de Rio Branco, em nível varejista, em dois cenários diferentes: 1) o mercado levantado neste estudo, o qual contou, entre 1999 e 2006, conforme já mencionado, com um governo fomentando o desenvolvimento, num nível sustentável, do setor florestal local; e (2) aquele atuando em 1996, quando não existiam políticas públicas florestais bem definidas.

\section{Metodologia de análise dos dados}

A comercialização de madeira serrada em Rio Branco foi analisada considerando-se os aspectos da estrutura e conduta do mercado local desses produtos e obedecendo aos procedimentos descritos a seguir.

Análise da estrutura do mercado

$\mathrm{Na}$ abordagem da estrutura do mercado aqui desenvolvida, foram avaliados dois dos três tópicos propostos por Braga (1980), Mendes (1989 e 1994), Cramer; Jensen (1991), Marques; Aguiar (1993) e Duerr (1993) para compor estudos sobre esse tema: grau de concentração no mercado e grau de diferenciação dos produtos.

\section{a) Grau de concentração}

$\mathrm{Na}$ identificação e avaliação do grau de concentração, conforme sugerem Labini (1984) e Kon (1994), foi utilizada, como variável básica, o volume de venda de madeira serrada pelos depósitos pesquisados. 
Ressalte-se que esta análise do grau de participação das firmas na comercialização de madeira serrada foi subsidiada pelo cálculo da relação de concentração e do índice de Herfindahl-Hirschmam. A escolha dessas técnicas partiu dos relatos de Carlton; Perloff (1994) e Cabral (1998), os quais apontam tais índices como os mais empregados para medir a concentração num mercado.

\section{a.1) Relação de concentração}

No sentido de se quantificar a relação de concentração na venda de madeira serrada e existente no mercado em questão, fez-se uso da seguinte expressão matemática, indicada por Kon (1994):

$$
C_{k}=\sum_{i=0}^{k} P_{i}
$$

Em que: $\boldsymbol{C}_{\boldsymbol{k}}=$ a relação de concentração para a comercialização do recurso madeireiro, até a firma $k$; $\boldsymbol{P}_{i}=$ participação percentual da firma $i$ entre $n$ firmas analisadas.

Os resultados do cálculo da relação de concentração gerados nesta pesquisa serviram, posteriormente, para se identificar a estrutura do mercado em questão. Nesse sentido, foi levada em consideração a seguinte classificação, apresentada por Caves (1982):

- o mercado analisado teria uma estrutura típica de um oligopólio tipo I caso as suas oito maiores firmas respondessem, no mínimo, por 50\% da venda de madeira serrada, com as vinte maiores contribuindo com uma parcela maior ou igual a $75 \%$ do total desses itens e nenhuma firma detivesse, sozinha, mais que 10 a $15 \%$ da comercialização do mercado;

- o perfil da área de estudo apresentar-se-ia como um exemplo de oligopólio tipo II se as suas oito maiores firmas participassem com percentuais iguais ou superiores a $33 \%$ da venda de madeira serrada e as vinte maiores detivessem uma parcela maior ou igual a $75 \%$ do total desses itens;

- o setor em questão seria visto como constituído por indústrias não concentradas para o caso em que as suas oito maiores firmas respondessem com menos que 33\% do volume total comercializado no mercado;

- o mercado pesquisado seria caracterizado como um grupo de indústrias competitivas na situação em que as suas quatro maiores firmas detivessem uma participação menor que $10 \%$ da comercialização total do mercado.

\section{a.2) Índice de Herfindahl-Hirschman (HH)}

Foi também calculado, para avaliação do grau de concentração, o índice Herfindahl-Hirschman, como aconselham Klemperer (1996), Mendes (1998) e Santos; Santana (2003), levando em conta a seguinte fórmula:

$$
H H=\sum_{i=0}^{n} P_{i p}^{2}
$$

Em que: $H H=$ o índice Herfindahl-Hirschman, segundo Klemperer (1996), Mendes (1998) e Santos; Santana (2002);

$P_{i p}=$ a participação percentual (onde $100 \%=100$ ) da firma $i$ no mercado.

Para se analisar o índice Herfindahl-Hirschman obtido nesse estudo, foram tomados como critérios os recomendados por Klemperer (1996), Mendes (1998) e Santos; Santana (2003), sintetizados a seguir:

- Quando o valor de $H H$ obtido tende a 0 , o mercado analisado tende a uma competição perfeita.

- Na eventualidade do $H H$ calculado ser menor que 1.000, o mercado será altamente competitivo, e assim possuidor de uma baixa concentração.

- Quando o $H H$ gerado está entre 1.000 e 1.800 , o mercado é visto como tendo uma concentração moderada.

- Para a situação em que o $H H$ obtido é maior que 1.800 , o mercado analisado é altamente concentrado.

- Se o $H H$ identificado é igual a 10.000, o mercado é um monopólio. 


\section{b) Grau de diferenciação dos produtos}

A abordagem sobre o grau de diferenciação dos produtos seguiu, nesta pesquisa, dois enfoques.

Considerando proposta divulgada por Mendes (1994), na análise do grau de diferenciação do produto foi avaliada a adoção, nos depósitos locais, das seguintes ações: 1) disponibilidade de prontaentrega da mercadoria; 2) garantia da qualidade para seus produtos; e 3) oferecimento de frete grátis da madeira serrada.

$\mathrm{Na}$ segunda abordagem, adotando indicação de Silva (2000), foram levadas em conta as respostas dos empresários sobre quais os itens que eles consideram como um diferenciador favorável do seu depósito em relação às firmas concorrentes. Nesse procedimento, foram propostas, aos entrevistados, como fatores diferenciadores das suas firmas, as seguintes opções: 1) preço do produto; 2) produto em si, diferenciado nos subitens espécie madeireira utilizada e qualidade do produto; 3) fornecimento de serviços especiais; 4) método de distribuição dos produtos; 5) realização de promoções de venda; e 6) outros.

Conduta das firmas

Entre os conceitos, propostos por Steele et al. (1971), Kotler (1994) e Mendes (1994), no enfoque da conduta do mercado revendedor de madeira serrada de Rio Branco, foram levadas em consideração as políticas de formação de preços e também as diretrizes administrativas ligadas à promoção.

\section{a) Políticas de preço}

Embasado na sistemática empregada por Silva (2000, 2004 e 2007) para a análise das políticas de formação de preço, foram listadas e avaliadas as fontes de informação que os empresários locais usam para fixar o valor de venda da sua madeira serrada. Visando auxiliar essa identificação, foram sugeridos, nas entrevistas, como possíveis subsídios para tais políticas, os itens: 1) custo de comercialização mais uma margem de lucro; 2) preço médio dos concorrentes; 3) tabela de preço do sindicato; e 4) outros.

\section{b) Políticas de promoção}

Com base nos itens sugeridos por Kotler (1994) no estudo das políticas de promoção praticadas no setor madeireiro de Rio Branco, foi identificada e discutida a ocorrência, nesse segmento, dos procedimentos gerenciais ligados aos temas, tais como: 1) publicidade ou propaganda; 2) promoção de venda propriamente dita; e 3) relações públicas.

Para tal, foram adotados os seguintes conceitos citados por Zober (1971) e Kotler (1994):

- Publicidade: um meio de apresentação impessoal para promover ideias, bens e serviços, executadas por um patrocinador identificado.

- Promoção de venda: um incentivo de curto prazo que encoraja a venda de um bem.

- Relações públicas: um grupo de programas que melhora, mantém ou protege a imagem da firma ou do produto.

É oportuno citar que, nesta pesquisa, mediante símbolos usados por Nautiyal et al. (1985) e Klemperer (1996), as firmas foram codificadas como $C_{4}$, indicando as quatro empresas com as maiores percentagens de concentração no mercado em 2006 e Outras $_{4}$, representando aquelas que não tinham uma participação significativa nesse mercado (as vinte e três firmas restantes amostradas em 2006). Com isso, foi possível avaliar e discutir os resultados gerados neste estudo em três diferentes níveis: $1^{\circ}$ ) o mercado como um todo (todas as firmas amostradas); $2^{\circ}$ ) as firmas $\mathrm{C}_{4}$; e $3^{\circ}$ ) o grupo de depósitos que compunham a classificação Outras 4 .

\section{RESULTADOS E DISCUSSÕES}

\section{Estrutura do mercado}

$\mathrm{O}$ estudo abordando os graus de concentração e de diferenciação do produto no mercado pesquisado gerou os seguintes pontos:

Grau de concentração

O volume de madeira serrada comercializado pelos depósitos de Rio Branco no período de 20052006 está indicado na tabela 1. 
Tabela 1. Participação dos depósitos de Rio Branco na venda de madeira serrada, 2005-6.

Table 1. Participation of the timber retailers established in Rio Branco, in the lumber sale, 2005-6.

\begin{tabular}{|c|c|c|c|c|c|c|}
\hline \multirow[b]{2}{*}{$\begin{array}{l}\text { Depósito } \\
\text { no }^{\text {o }}\end{array}$} & \multicolumn{3}{|c|}{ Valores - Ano 2005} & \multicolumn{3}{|c|}{ Valores - Ano 2006} \\
\hline & $\begin{array}{c}\text { Volume } \\
\text { de madeira } \\
\text { comercializada } \\
\left(\mathrm{m}^{3} / \text { ano }\right)\end{array}$ & $\begin{array}{c}\text { Participação } \\
\text { individual } \\
\text { no mercado } \\
\text { total } \\
(\%)\end{array}$ & $\begin{array}{l}\text { Participação } \\
\text { acumulada } \\
\qquad(\%)\end{array}$ & $\begin{array}{c}\text { Volume de } \\
\text { madeira } \\
\text { comercializada } \\
\left(\mathbf{m}^{3} / \text { ano }\right)\end{array}$ & $\begin{array}{c}\text { Participação } \\
\text { individual } \\
\text { no mercado } \\
\text { total } \\
(\%) \\
\end{array}$ & $\begin{array}{c}\text { Participação } \\
\text { acumulada } \\
(\%)\end{array}$ \\
\hline 1 & 800,00 & 13,28 & 13,28 & 1100,00 & 13,04 & 13,04 \\
\hline *2 & 800,00 & 13,28 & 26,57 & 1000,00 & 11,85 & 24,89 \\
\hline 3 & 750,00 & 12,45 & 39,02 & 900,00 & 10,67 & 35,55 \\
\hline 4 & 600,00 & 9,96 & 48,99 & 800,00 & 9,48 & 45,03 \\
\hline *5 & 700,00 & 11,62 & 60,61 & 500,00 & 5,93 & 50,96 \\
\hline 6 & 450,00 & 7,47 & 68,08 & 600,00 & 7,11 & 58,07 \\
\hline 7 & 500,00 & 8,30 & 76,39 & 400,00 & 4,74 & 62,81 \\
\hline *8 & 350,00 & 5,81 & 82,20 & 400,00 & 4,74 & 67,55 \\
\hline 9 & 0,00 & 0,00 & 82,20 & 562,00 & 6,66 & 74,21 \\
\hline *10 & 0,00 & 0,00 & 82,20 & 500,00 & 5,93 & 80,14 \\
\hline 11 & 186,90 & 3,10 & 85,30 & 248,70 & 2,95 & 83,08 \\
\hline 12 & 150,00 & 2,49 & 87,79 & 180,00 & 2,13 & 85,22 \\
\hline 13 & 0,00 & 0,00 & 87,79 & 248,70 & 2,95 & 88,16 \\
\hline 14 & 0,00 & 0,00 & 87,79 & 248,70 & 2,95 & 91,11 \\
\hline 15 & 100,00 & 1,66 & 89,46 & 80,00 & 0,95 & 92,06 \\
\hline 16 & 80,00 & 1,33 & 90,78 & 100,00 & 1,19 & 93,24 \\
\hline 17 & 80,00 & 1,33 & 92,11 & 100,00 & 1,19 & 94,43 \\
\hline 18 & 80,00 & 1,33 & 93,44 & 100,00 & 1,19 & 95,62 \\
\hline 19 & 70,00 & 1,16 & 94,60 & 80,00 & 0,95 & 96,56 \\
\hline *20 & 40,00 & 0,66 & 95,27 & 50,00 & 0,59 & 97,16 \\
\hline 21 & 50,00 & 0,83 & 96,10 & 80,00 & 0,95 & 98,10 \\
\hline 22 & 50,00 & 0,83 & 96,93 & 50,00 & 0,59 & 98,70 \\
\hline 23 & 50,00 & 0,83 & 97,76 & 30,00 & 0,36 & 99,05 \\
\hline 24 & 50,00 & 0,83 & 98,59 & 25,00 & 0,30 & 99,35 \\
\hline 25 & 40,00 & 0,66 & 99,25 & 22,50 & 0,27 & 99,61 \\
\hline *26 & 20,00 & 0,33 & 99,58 & 20,00 & 0,24 & 99,85 \\
\hline 27 & 25,00 & 0,42 & 100,00 & 12,50 & 0,15 & 100,00 \\
\hline TOTAL & $6.021,90$ & 100,00 & - & $8.438,10$ & 100,00 & - \\
\hline
\end{tabular}

Dados básicos coletados e processados pelos autores; (*) Firma verticalizada; as firmas 9, 10, 13 e 14 passaram a atuar no mercado apenas a partir de 2006.

Os resultados sobre a participação acumulada dos depósitos de Rio Branco na venda de madeira serrada mostram que, segundo a classificação apresentada por Caves (1982), o mercado em questão pode ser caracterizado como um exemplo de oligopólio tipo II. Cabe aqui ressaltar que tal categorização foi a mesma a que chegou Silva (2000) sobre esse mercado no ano de 1996.

Uma segunda informação, gerada a partir dos dados dessa tabela, é que os índices de HerfindahlHirschman, calculados para os anos de 2005 e 2006, foram 930,21 e 762,72, respectivamente. Com isso, esse mercado, de acordo com os critérios sugeridos por Klemperer (1996), Mendes (1998) e Santos; Santana (2003), tinha um perfil altamente competitivo, com uma baixa concentração na venda de madeira serrada.

Saliente-se que, na pesquisa feita por Silva (2000), o índice HH calculado para o segmento varejista em atividade em Rio Branco, em 1996, foi de 1.381,667, fato que o caracterizava como apresentando uma concentração moderada. Por esse motivo, é plausível o argumento de que foi observada, no período 1996-2006, uma tendência desse mercado em se tornar menos concentrado na comercialização do seu produto.

Cabe aqui acrescentar que Silva (2003), analisando o grupo das marcenarias atuando em Rio Branco, em 1996, obteve um índice Herfindahl-Hirschman de 103,95. Assim sendo, esse processo de 
produção de móveis, a exemplo do mercado revendedor de madeira serrada, enfocado neste artigo, pode ser considerado como sendo, também, altamente competitivo. Contudo, levando-se em conta os valores de $\mathrm{HH}$, pode-se afirmar que o segmento dos depósitos aqui analisado (possuidor de índices HerfindahlHirschman de 930,21 e 762,72, nos anos de 2005 e 2006), era, de certa forma, mais concentrado na venda da sua mercadoria que o grupo das movelarias (com um HH de 103,95) era no uso industrial de madeira.

Por outro lado, o mercado de artefatos de madeira em atividade no Pará em 1997, quando estudado por Santos; Santana (2003), gerou o índice HH de 785,7. Assim, esse setor se assemelhava ao grupo dos depósitos atuantes em Rio Branco em 2005-6: ambos eram altamente competitivos, com uma concentração moderada nos seus processos de produção e de venda das suas respectivas mercadorias.

Verifica-se ainda, na tabela 1, que no ano de 2006 ocorreu a entrada de quatro novas firmas revendedoras de madeira serrada no município de Rio Branco, em relação a 2005. Com isso, houve uma alteração, de um ano para o outro, da composição do mercado analisado: embora as firmas que passaram a atuar nesse mercado tivessem volume de venda superior a alguns depósitos que já estavam em atividade no ano de 2005, no cômputo geral esse fato veio a diminuir a concentração na venda de madeira serrada nesse segmento de mercado. Assim sendo, a madeira serrada comercializada pelos depósitos nessa capital passou a ser vendida num cenário mais competitivo.

Com respeito à entrada de firmas nesse mercado, Sousa (2007), identificando e analisando o grau de obstáculo para um depósito iniciar as suas atividades em Rio Branco, em 2005-6, constatou que o maior limitante seria a dificuldade que tal firma enfrentaria para conseguir obter as documentações exigidas pelos órgãos ambientais locais (enfocando mais aspectos ambientais em si, que legais, tais como a titulação da área de onde é extraída a madeira). Já Silva (2000) observou que, em 1996, as restrições que um depósito enfrentaria, caso desejasse se instalar nessa capital, para $80 \%$ dos empresários amostrados, seria a necessidade de uma quantia significativa de capital para comprar a sua matéria-prima, enquanto que os restantes $12 \%$ dos entrevistados citaram como barreiras ao início das operações a disponibilidade de matéria-prima para comercializar.

Grau de diferenciação dos produtos

$\mathrm{Na}$ avaliação do grau de diferenciação dos produtos comercializados pelos depósitos no setor madeireiro em Rio Branco, os seguintes resultados foram identificados.

\section{a) Diferenciação dos produtos segundo a prestação de serviços especiais aos clientes}

Uma análise das respostas dos empresários madeireiros abordados no levantamento de dados para este estudo revela que o produto comercializado pelos depósitos atuantes na cidade de Rio Branco, no período 2005-6, não se diferenciava de um revendedor para o outro. Essa afirmação se embasa nos seguintes pontos:

I) Verificou-se que todos os entrevistados dispunham, no período em análise, de mercadoria para prontaentrega, no sentido de atender mais que a metade de seus pedidos.

II) Observou-se que todas as lojas revendedoras de madeira serrada pesquisadas se comprometiam em repor os produtos vendidos caso eles apresentassem defeito. Assim sendo, esse procedimento caracterizava a ocorrência da garantia da qualidade da madeira serrada por eles comercializada.

Cabe aqui mencionar que os empresários amostrados informaram que, embora eles ofereçam à sua clientela a garantia da qualidade dos seus produtos, a necessidade da reposição de uma mercadoria com defeito é um evento raro de ocorrer nas suas firmas. Essa afirmação se deve ao fato de que, segundo as respostas, a madeira serrada possui as qualidades desejadas pelo comprador. Além disso, os donos dos depósitos reportaram que o cliente examina o produto antes de adquiri-lo. Assim, não há justificativa para uma solicitação, por parte de quem adquire a mercadoria, para que os empresários troquem a madeira comercializada.

III) A totalidade dos donos de depósitos entregava suas mercadorias, sem custo adicional ao cliente, no local por ele indicado. Salienta-se que, como condicionante para a disponibilidade desse serviço especial aos seus consumidores, os entrevistados listaram, apenas, o fato de que o ponto de entrega não fosse fora de Rio Branco, não se referindo, então, a um volume mínimo de compra como um segundo limitante para o oferecimento desse frete grátis ao comprador do produto. 
Um ponto a realçar, ainda com referência às políticas de garantia da qualidade e pronta-entrega do produto, assim como em relação ao oferecimento de frete grátis aos clientes, é que, conforme o estudo apresentado por Silva (2000), tais serviços caracterizavam o grupo dos depósitos atuantes em Rio Branco, no ano de 1996, de duas formas diferentes:

- Levando-se em conta que as empresas com maior concentração na venda de madeira serrada tinham uma maior frequência na pronta-entrega dos seus produtos que as firmas com menor participação no mercado, têm-se a pronta-entrega da mercadoria caracterizando-se como um diferenciador de uma firma das suas concorrentes nesse segmento comercial.

- Considerando que a quase totalidade dos depósitos analisados oferecia, aos seus clientes, a garantia da qualidade dos seus produtos, como também disponibilizavam frete grátis na comercialização da sua mercadoria, pode-se argumentar que tais itens não eram fatores que diferenciavam as firmas com maiores participações percentuais na venda dessa mercadoria das demais empresas do mercado em análise.

Do exposto, verifica-se que, enquanto em 1996 a pronta-entrega dos produtos era um indicador para diferenciar as firmas $\mathrm{C}_{4}$ dos depósitos integrantes do grupo Outras 4 , em 2006 tal realidade não se repetia, pois todas as firmas analisadas adotavam esse procedimento na comercialização do seu produto.

Aliado a esse fato, tem-se que os demais itens propostos na literatura como indicadores da diferenciação de produtos (garantia da qualidade e oferecimento de frete grátis) não eram, nos dois períodos abordados para analisar o mercado revendedor de madeira serrada de Rio Branco, fatores que podiam distinguir o produto comercializado por uma firma daquele vendido por outra empresa.

\section{b) Pontos que diferenciavam os integrantes do setor madeireiro de Rio Branco}

A tabela 2 lista as características que os proprietários dos depósitos estudados consideravam como as que diferenciavam as suas firmas das empresas dos seus concorrentes, nos anos de 2005-6.

Observando os valores indicados na tabela 2, verifica-se que, no grupo total dos depósitos de Rio Branco, a característica da sua mercadoria (considerando, em conjunto, a espécie madeireira usada na sua produção e a qualidade do produto em si) se constituía no principal item que os proprietários dessas firmas consideravam como diferenciador positivo da sua empresa em relação às concorrentes.

Um detalhamento maior desses números revela que, para o empresário entrevistado, o preço, quando comparado aos itens espécie e qualidade da mercadoria em separado, era o fator que mais distinguia, favoravelmente, o seu depósito das demais firmas do mercado.

Outra análise das informações apresentadas nessa tabela permite constatar que a totalidade dos donos das firmas $\mathrm{C}_{4}$ indicou que a característica da sua mercadoria (levando em conta os itens espécie e a qualidade da madeira serrada) era o ponto de maior relevância que distinguia a sua empresa dos seus concorrentes.

Tabela 2. Fatores que diferenciavam os depósitos revendedores de madeira serrada de Rio Branco, 2005-6. Table 2. Factors that differentiate the timber retailers in Rio Branco, 2005-6.

\begin{tabular}{lccc}
\hline \multirow{2}{*}{ Fator } & \multicolumn{3}{c}{ Posição no mercado } \\
\cline { 2 - 4 } & $\mathbf{C}_{\mathbf{4}}(\boldsymbol{\%})$ & Outras $_{\mathbf{4}}(\boldsymbol{\%})$ & Média geral $\mathbf{( \% )}$ \\
\hline Preço & 50,00 & 73,91 & 70,37 \\
Produto & 100,00 & 69,57 & 74,07 \\
$\bullet \quad$ Espécie & 25,00 & 8,70 & 11,11 \\
- Qualidade & 75,00 & 56,52 & 59,26 \\
Serviços especiais & 0,00 & 8,70 & 7,41 \\
Método de distribuição & 0,00 & 8,70 & 7,41 \\
\hline
\end{tabular}

Dados básicos coletados e processados pelos autores. Pelo fato de que a formulação da pergunta permitia aos donos das firmas entrevistadas mais de uma resposta, a somatória dos valores, nesta tabela, excede a $100 \%$.

Um segundo fator em importância para essa diferenciação, segundo tais empresários, seria o preço. Porém, se comparados, em separado, os fatores diferenciadores das firmas, a qualidade do produto comercializado era vista como o de maior relevância, seguida pelo preço e, por último, tinha-se a espécie da madeira para distinguir uma firma das suas competidoras. 
Salienta-se que esse cenário em que a qualidade da madeira, para mais da metade dos donos das revendas analisadas neste estudo, era um diferenciador de uma firma das suas concorrentes, não foi indicado, explicitamente, pela totalidade dos entrevistados quando eles citaram que a característica da sua mercadoria atende às necessidades do cliente. Mais especificamente, quando é avaliada a prática de garantia da qualidade dos produtos vendidos e os fatores que fazem necessária a reposição de artigos defeituosos, os atributos e propriedades da madeira comercializada por esses depósitos não se mostraram, ainda que indiretamente e na visão dos empresários madeireiros amostrados, como diferenciador de uma empresa das concorrentes.

Por outro lado, para os proprietários das empresas Outras 4 , o preço era o fator que mais diferenciava sua firma dos demais depósitos de Rio Branco, tanto quando comparado com as características gerais do produto comercializado quanto em relação à espécie e qualidade da madeira serrada consideradas em separado.

Cabe enfatizar que o fato aqui constatado de as firmas (tanto aquelas analisadas no mercado como um todo como as empresas integrantes do grupo Outras 4 ), buscarem se diferenciar, via preço, das suas concorrentes, contraria o que preconiza a literatura econômica, quando esta aborda a formação de preço numa estrutura de oligopólio, como identificado nesse estudo.

Diante do exposto, cabe aqui comentar que, para os empresários pesquisados, serviços especiais e método de distribuição são pontos que menos diferenciam a sua firma dos seus concorrentes, em vista de todos realizarem essa prática. Tal observação merece destaque, principalmente, porque a afirmação dos donos das firmas analisadas contraria a literatura consultada, citada neste artigo, segundo a qual a avaliação da prática de serviços especiais, por uma empresa, é um útil indicador na análise do grau de diferenciação dos produtos.

Além disso, mesmo que um pouco menos de $10 \%$ dos entrevistados tenham a prática de serviços especiais e método de distribuição como fatores distinguindo o seu depósito dos concorrentes, tal fato não ocorre, conforme já mencionado neste estudo. Nesse sentido, tem-se que esses empresários devem reavaliar suas políticas ligadas à comercialização dos seus produtos, fazendo com que tais serviços e modelos de distribuição resultem, efetivamente, em fator de diferenciação positiva da sua firma em relação às demais integrantes do mercado em questão.

Um ponto a destacar é que nenhum dos empresários entrevistados indicou a origem da sua madeira serrada (vinda, ou não, de uma floresta manejada) como um fator-chave para distinguir a sua empresa dos demais depósitos locais. A partir dessa situação, pode-se inferir que, embora não tenha sido expressamente indicado pelos entrevistados, o importante para o vendedor, no sentido de atender à demanda do seu cliente local, é que o seu produto tenha sido explorado numa floresta com a permissão dos órgãos ambientais, independentemente se numa área de conversão ou numa floresta manejada.

É oportuno mencionar o estudo de Silva (2000), que revela que, para os donos de depósitos de Rio Branco, em 1996, tanto considerando o mercado como um todo como quando ele é diferenciado em dois segmentos distintos de firmas $\left(\mathrm{C}_{4} \mathrm{e}\right.$ Outras $\left._{4}\right)$, a qualidade do produto era o item que os empresários consideravam como o que mais diferenciava o seu empreendimento dos concorrentes.

$\mathrm{O}$ segundo ponto mais relevante era o preço da madeira serrada, seguido, em ordem de importância, da oferta de serviços especiais, do método de distribuição e da espécie da madeira. Já no grupo das firmas $\mathrm{C}_{4}$, o item distribuição era visto como no mesmo nível de relevância que o preço e mais importante que serviços especiais e espécie madeireira, no sentido de distinguir uma firma das suas concorrentes.

Assim como foi constatado no grupo de depósitos de Rio Branco no período 2005-6, também em 1996 a característica do produto e a oferta de serviços especiais (com destaque para a garantia da qualidade da mercadoria vendida) não se apresentavam como diferenciadores de uma firma das suas concorrentes. Essa afirmação se embasa no fato de que, em 1996, todos os empresários visitados argumentam que ofereciam, ao mercado, madeira serrada de acordo com as exigências dos compradores, o que evitava, assim, a necessidade de repor mercadorias defeituosas. Dessa forma, a qualidade desse produto e, portanto, a garantia da sua qualidade não eram, então, itens que podiam distinguir uma empresa das demais em atividade nesse mercado.

\section{Conduta do mercado}

Os resultados sobre a conduta do mercado revendedor de madeira serrada de Rio Branco, em atividade em 2005-6, são apresentados a seguir. 
Política de preço

As políticas de preço adotadas pelos depósitos entrevistados estão sintetizadas na tabela 3.

Tabela 3. Política de formação de preço nos depósitos de Rio Branco, 2005-6.

Table 3. Pricing policy played by the timber retailers acting in Rio Branco, 2005-6.

\section{Procedimento}

Custo + Margem de lucro

Média de preço dos concorrentes

Não respondeu

Dados básicos coletados e processados pelos autores.
Posição no mercado

\begin{tabular}{ccc}
$\mathrm{C}_{\mathbf{4}}(\boldsymbol{( \% )}$ & Outras $_{\mathbf{4}}(\boldsymbol{\%})$ & Média geral $(\%)$ \\
75,00 & 78,26 & 77,78 \\
0,00 & 21,74 & 18,52 \\
25,00 & 0,00 & 3,70 \\
\hline
\end{tabular}

Constata-se, pelas informações que constam da tabela 3, que a maioria dos depósitos de Rio Branco fixava o preço de venda do seu produto considerando o seu custo de comercialização mais uma margem de lucro.

Conforme se pode observar, os empresários entrevistados, no período pesquisado, estavam mais próximos do modelo identificado por Hall; Hitch (1939), que aqueles apresentados por Mendes (1994) e Varian (1997). Mais especificamente, os proprietários das firmas analisadas estavam estabelecendo o preço de venda da sua mercadoria a partir do seu custo operacional mais uma margem de lucro, e não, como num cartel, em função de acordos entre as empresas ou mesmo seguindo os valores estipulado pela firma líder do mercado.

Os números dessa tabela indicam, também, que nenhuma das firmas $\mathrm{C}_{4}$ tinha média de preço dos concorrentes como fonte de referência na formação do preço de venda da sua mercadoria nesse mercado. Por outro lado, em torno de $20 \%$ dos depósitos do grupo Outras 4 , e do mercado como um todo, usavam os valores médios das empresas do mercado para fixarem o preço de sua mercadoria.

Porém, segundo Silva (2000), em 1996, o cenário era diferente: a média dos preços dos concorrentes era o que mais embasava tanto o grupo total de depósitos de Rio Branco como as suas firmas $\mathrm{C}_{4}$ e Outras 4 , na fixação do preço da sua madeira serrada.

Do exposto, tem-se que ocorreu uma mudança, no período analisado, nas políticas adotadas para a definição do preço de venda do produto. Essa realidade pode ser correlacionada com a mudança na concentração no mercado em questão, entre 1996 e 2005-6. Em outras palavras, se em 1996, quando foi constatado um mercado moderadamente concentrado, a fixação do valor de venda da madeira serrada era feita segundo o preço médio praticado nesse mercado, no período 2005-6, quando foi identificado um mercado com uma baixa concentração na comercialização da sua mercadoria, as firmas passaram a definir o valor de venda do seu produto considerando o custo de comercialização mais uma margem de lucro.

Complementando, é importante enfatizar que, seguindo os conceitos de políticas/estratégias de preço limite, indicados por Azevedo (1998) e Kupfer (2002), como obstáculos à entrada de novas firmas no mercado, os depoimentos dos madeireiros acreanos permitem inferir que, quando as empresas adotavam as suas políticas de fixação de preço, elas não usavam tais procedimentos para determinar (declaradamente ou de forma intencional) um "preço limite" que impossibilitasse a entrada de novas firmas no mercado.

Políticas de promoção

As políticas de promoção praticadas pelos depósitos de Rio Branco são apresentadas a seguir.

\section{a) Práticas de propaganda}

A tabela 4 apresenta a participação das ferramentas de propaganda nas estratégias de promoção adotadas pelos depósitos de Rio Branco.

Os valores apresentados nessa tabela revelam que as firmas madeireiras analisadas realizavam, no período 2005-6, mais propaganda dos seus produtos comprando espaços em listas telefônicas que em revistas, rádios ou cartazes.

Cabe aqui citar que, de acordo com Silva (2000), em 1996, pouco mais de 79\% dos depósitos vendedores de madeira serrada de Rio Branco não usavam instrumentos como propaganda em lista 
telefônica, jornais, rádio/TV e cartaz para auxiliar na divulgação das suas firmas ou das mercadorias lá comercializadas.

Tabela 4. Políticas de promoção, via propaganda, adotadas pelos depósitos de Rio Branco, 2005-6.

Table 4. Promotion policy, using propaganda, adopted by the timber retailers in Rio Branco, 2005-6.

\begin{tabular}{lccc}
\hline \multirow{2}{*}{ Frequência } & \multicolumn{3}{c}{ Posição no mercado (\%) } \\
\cline { 2 - 4 } & $\mathbf{C}_{\mathbf{4}}$ & Outras $_{\mathbf{4}}$ & Média geral \\
\hline Revista/jornal & 25,00 & 13,04 & 14,81 \\
Rádio/TV & 75,00 & 21,74 & 29,63 \\
Cartaz & 50,00 & 17,39 & 22,22 \\
Lista telefônica & 100,00 & 60,87 & 66,67 \\
\hline
\end{tabular}

Dados básicos coletados e processados pelos autores. Pelo fato de que a formulação da pergunta permitia aos donos das firmas entrevistadas mais de uma resposta, a somatória dos valores, nesta tabela, excede a $100 \%$.

Assim sendo, pode-se argumentar que houve, durante o período avaliado, uma significativa alteração na prática, pelo grupo das empresas analisadas nesse estudo, de políticas voltadas à promoção de venda de madeira serrada: enquanto que, em 1996, tais procedimentos eram adotados por um número relativamente pequeno de firmas, no período 2005-6 os empresários entrevistados passaram a dar uma maior relevância à propaganda como meio para elevar o volume de venda do seu depósito, destacando-se o uso de lista telefônica, empregada por mais da metade das firmas aqui analisadas.

\section{b) Promoção de venda}

A tabela 5 relaciona as práticas de promoção de venda no grupo de revendedores de madeira serrada de Rio Branco no período de 2005-6.

Tabela 5. Prática de promoção de venda realizada pelos depósitos de Rio Branco, 2005-6.

Table 5. Sales promotion practices carried out by the timber retails established in Rio Branco, 2005-6.

\begin{tabular}{lccc}
\hline \multirow{2}{*}{ Frequência } & \multicolumn{3}{c}{ Posição no mercado (\%) } \\
\cline { 2 - 4 } & $\mathbf{C}_{\mathbf{4}}$ & Outras $_{\mathbf{4}}$ & Média geral \\
\hline Distribui brindes & 50,00 & 8,70 & 14,81 \\
Dá desconto & 100,00 & 100,00 & 100,00 \\
Faz demonstração & 75,00 & 52,17 & 55,56
\end{tabular}

Dados básicos coletados e processados pelos autores. Pelo fato de que a formulação da pergunta permitia aos donos das firmas entrevistadas mais de uma resposta, a somatória dos valores, nesta tabela, excede a $100 \%$.

Tem-se, na tabela 5, que todas as firmas revendedoras de madeira davam, nos anos 2005 e 2006, descontos nos preços de sua mercadoria, quando os valores das vendas desses produtos eram pagos à vista.

Outro fato que se verifica nessa tabela é que mais da metade das empresas analisadas fazia, no período estudado, demonstração do produto aos potenciais compradores.

Em síntese, as informações dessa tabela evidenciam que cerca de $15 \%$ dos depósitos de Rio Branco ofereciam brindes ao cliente.

Saliente-se que, embora as firmas revendedoras de madeira serrada em atividade em Rio Branco em 1996, conforme relato de Silva (2000), tivessem o hábito de fazer distribuição de brindes e dar descontos nas suas vendas à vista, não era usual que esses depósitos demonstrassem o produto aos seus clientes.

\section{c) Relações públicas}

A tabela 6 revela os procedimentos administrativos ligados às relações públicas praticados pelo setor de depósitos de Rio Branco, em 2005-6.

Os dados da tabela 6 mostram que quase $41 \%$ dos depósitos faziam doações, na forma de madeira serrada, às entidades, organizações e instituições tais como escolas e igrejas estabelecidas em Rio Branco.

Outrossim, verifica-se, ainda nessa tabela, que um percentual significativamente pequeno das empresas amostradas difundia, via folders ou outros impressos similares, informações aos seus potenciais 
clientes sobre as características das suas mercadorias. Saliente-se que tais firmas agem assim como uma forma de relações públicas, no sentido de melhorar, manter ou proteger a imagem da sua madeira serrada.

Tabela 6. Procedimentos de relações públicas executados pelos depósitos de Rio Branco, 2005-6.

Table 6. Public relations procedures executed by the timber retails working in Rio Branco, 2005-6.

\begin{tabular}{lccc}
\hline \multirow{2}{*}{ Frequência } & \multicolumn{3}{c}{ Posição no mercado (\%) } \\
\cline { 2 - 4 } & $\mathbf{C}_{\mathbf{4}}$ & Outras $_{\mathbf{4}}$ & Média geral \\
\hline Doação & 50,00 & 39,13 & 40,74 \\
Informação ao usuário & 25,00 & 0,00 & 3,70 \\
Não respondeu & 50,00 & 60,87 & 59,26 \\
\hline
\end{tabular}

Dados básicos coletados e processados pelos autores. Pelo fato de que a formulação da pergunta permitia aos donos das firmas entrevistadas mais de uma resposta, a somatória dos valores, nesta tabela, excede a $100 \%$.

Um ponto que cabe aqui destacar é que nenhuma das firmas pesquisadas dava informações para a imprensa sobre a madeira serrada por elas comercializada. Tal fato se deve a dois pontos ligados à relação entre o empresário madeireiro acreano e a imprensa de Rio Branco. Mais especificamente, por um lado, não é usual os meios de comunicação nessa capital entrevistarem os donos das firmas madeireiras locais ou mesmo publicar matérias que divulguem os produtos comercializado por esse setor. Por outro lado, o empresariado entrevistado não demonstrou conhecer os impactos positivos de divulgar sua mercadoria nos jornais ou nas redes de rádio e televisão locais. Assim, não havendo interesse dos meios de comunicação locais em divulgar o produto madeireiro acreano, como também o empresariado analisado não criando demanda por difundir a sua mercadoria, informações desse produto não chegam aos clientes via imprensa, como identificado nesse estudo.

Segundo Silva (2000), em 1996 a maioria dos depósitos de Rio Branco não difundia informações sobre seus produtos, nem aos seus potenciais clientes nem à imprensa. Aliado a esse fato, mais da metade dessas firmas não fazia doações de donativos, ou o fazia raramente, principalmente entre as empresas $\mathrm{C}_{4}$ desse setor.

\section{CONCLUSÕES}

A partir dos resultados gerados neste estudo sobre os aspectos da estrutura e conduta do mercado varejista de madeira serrada atuante em Rio Branco, em 2005-6, é possível que sejam inferidas as seguintes conclusões:

- Esse mercado era um oligopólio altamente competitivo na venda de madeira.

- Todas as firmas ofereciam garantia da qualidade, pronta-entrega e frete grátis dos produtos, de modo que tais serviços não diferenciavam a madeira comercializada por essas empresas.

- Embora, para os empresários, a qualidade da madeira distinguisse positivamente uma firma dos concorrentes, isso não ocorria, pois todos entregavam mercadoria conforme desejada pelo cliente.

- A maioria das empresas estabelecia o preço de venda considerando custo de comercialização mais uma margem de lucro.

- A lista telefônica era o principal meio de propaganda usado por essas firmas.

- Nesse mercado, adotava-se muito o desconto no preço à vista e a demonstração do produto aos compradores.

- Difundir informações e distribuir brindes ou doações eram ações pouco ou mesmo não adotadas nesse mercado.

\section{REFERÊNCIAS}

ABIMCI - Associação Brasileira da Indústria de Madeira Processada Mecanicamente. Estudo Setorial 2007 - Indústria de Madeira Processada Mecanicamente. Curitiba: ABIMCI, 2007. 41 p.

ACRE, Governo do Estado do Acre. Programa Estadual de Zoneamento Ecológico do Estado do Acre. Zoneamento Ecológico - Econômico do Acre Fase II: documento Síntese - Escala 1:250.000. Rio Branco: SEMA, 2006. 356 p. 
AZEVEDO, P. F. de. Organização industrial. In: PINHO, D. B.; VASCONCELLOS, M. A. S. de. Manual de economia. 3. ed. São Paulo: Saraiva, 1998. p. 195-222.

BAIN, J. S. Barrier to new competition. Cambridge: Harvard University, 1956.

BRAGA, H. C. Estrutura de mercado e desempenho da indústria brasileira: 1973/75. Rio de Janeiro: Editora da Fundação Getúlio Vargas, 1980. 169 p. (Série Teses: nº-6).

CABRAL, L. Economia industrial. E. McGraw-Hill de Portugal, 1998. 238 p.

CARLTON, D. W.; PERLOFF, J. M. Modern industrial organization. 2.ed. New York: Harper Collins College Publishers, 1994. 973 p.

CAVES, R. E. American industry, structure, conduct and performance. Princeton: Pricenton University Press, 1982.

CLARKE, R. Industrial economics. Cambridge: Blackwell, 1994. 300 p.

CRAMER, G. L.; JENSEN, C. W. Agricultural economics and agribusiness. Singapore: John Wiley e Sons, 1991. $530 \mathrm{p}$.

DUERR, W. A. Introduction to forest resources economics. Singapore: McGraw-Hill, 1993. 485 p.

GIL, A. C. Técnicas de pesquisa em economia. 2.ed. São Paulo: Atlas, 1995. 195 p.

GREGORY, G. R. Resource economics for foresters. New York: John Wiley e Sons, 1987. 477 p.

HALL, R. L.; HITCH, C. Price theory and business behavior. Oxford Economics Papers. n. 2. p. 12-45, 1939.

HASENCLEVER, L.; KUPFER, D. Introdução. In: HASENCLEVER, L.; KUPFER, D. (orgs.). Economia industrial: fundamentos teóricos e práticas no Brasil. 2. ed. Rio de Janeiro: Campos, 2002.

HAVEMAN, R. H.; KNOPF, K. A. O sistema de mercado. São Paulo: Pioneira, 1972. 261 p.

KLEMPERER, W. D. Forest resource economics and finance. New York: McGraw-Hill, 1996. 551 p.

KOTLER, P. Administração de marketing: análise, planejamento, implementação e controle. 3. ed. São Paulo: Atlas, 1994. 878 p.

KON, A. Economia industrial. São Paulo: Nobel, 1994. 212 p.

KUPFER, D. Barreiras estruturais à entrada. In: HASENCLEVER, L.; KUPFER, D. (orgs.). Economia industrial: fundamentos teóricos e práticas no Brasil. 2. ed. Rio de Janeiro: Campos, 2002. p. 109-128.

LABINI, P. S. Oligopólio e progresso técnico. São Paulo: Abril Cultural, 1984. 199 p. (Os Economistas).

MAGRATH, P. Methodologies for studying agricultural markets in developing countries. Chatam: Natural Resources Institute, 1992. 36 p. (Marketing Series).

MARQUES, P. V.; AGUIAR, D. R. D. Comercialização de produtos agrícolas. São Paulo: EDUSP, 1993. $299 \mathrm{p}$.

MENDES, J. T. da G.. Comercialização agrícola. Curitiba, UFPR, 1994. 98 p.

Economia agrícola. Curitiba: ZNT. 1998. 458 p.

Economia agrícola: princípios básicos e aplicações. Curitiba: Scientia et Labor: Editora da UFPR, 1989. 399 p.

MURRAY, B. C.; PRESTEMON, J. P. Structure and efficiency of timber markets. In: SILLS, E. O.; ABT, K. L. Forests in a market economy. Dordrecht: Kluwer Academic, 2003. p. 153-177. (Forestry Sciences, v. 72). 
NAUTIYAL, J. C.; SINGH, B. K.; MENEZES, O. Market structure and economic performance of forest products industry in Ontario and Canada. Canadian Journal of Forest Research. [S.1.], v. 15, n. 1, p. $115-125,1985$.

NOCE, R.; SILVA, M. L. da; CARVALHO, R. M. M. A.; SOARES, T. S. Concentração das exportações no mercado internacional de madeira serrada. Revista Árvore. Viçosa, v. 29, n. 3, p. 431-437, 2005.

RESENDE, M.; BOFF, H. Concentração industrial. In: KUPFER, D.; HASENCLEVER, L. (orgs.). Economia industrial: fundamentos teóricos e práticas no Brasil. 2. ed. Rio de Janeiro: Campus, 2002. p. 73-90.

SANTOS, M. A. S. dos; SANTANA, A. C. de. Concentração e poder de mercado das empresas de artefatos de madeira do estado do Pará. In: ENCONTRO NACIONAL DE ENGENHARIA DA PRODUÇÃO, 23, 2003, Ouro Preto. Anais... Santa Bárbara d'Oeste-SP: Associação Brasileira de Engenharia da Produção, 2003. Disponível em: <http://www.bancoamazonia.com.br/ bancoamazonia2/includes/institucional/arquivos/biblioteca/artigos/economiaregional/Concentracao_poder deMercado_empresasdeartefatosdemadeiradoPara.pdf>

SILLS, E. O.; ABT, K. L. Introduction. In: Forests in a market economy. Dordrecht: Kluwer Academic, 2003. p. 1-7. (Forestry Sciences, v. 72).

SILVA, C. R. L. da; LUIZ, S. Economia e mercados: introdução à economia. 14. ed. São Paulo: Saraiva, 1995. $204 \mathrm{p}$.

SILVA, J. C. G. L. da; GRAÇA, L. R.; NOJIMOTO, T. Estrutura de mercado do setor de papel e celulose no Brasil. In: ENCONTRO BRASILEIRO DE ECONOMIA E PLANEJAMENTO FLORESTAL, 2. 1991, Curitiba). Anais... Curitiba: EMBRAPA-CNPF, p. 485-499. 1992.

SILVA, Z. A. G. P. da G. e. Análise econômica da concentração no uso de madeira tropical pelo setor das marcenarias de Rio Branco, estado do Acre, 1996. Scientia Forestales. Piracicaba, n. 64, p. 48-58, 2003.

Estrutura do setor madeireiro no estado do Acre, 1996-2002. Cerne. Lavras, v. 11, n. 4, p. 389398, out./dez. 2005.

Market for timber products in the State of Acre. In: FUNTAC, Sustainable forest management in the Brazilian Amazon: Antimary State Forest-Acre-Brazil, Project PD 94/90-ITTO. Rio Branco: FUNTAC, 2004, v. 01, p. 145-188.

. Mercado de madeira serrada e móveis no estado do Acre. Rio Branco: FUNTAC, 66 p. 2007. $\overline{(C D U} 674.23$ (811.2)).

. Mercado madeireiro na Amazônia ocidental: estudo de caso no Acre. 2000. 196 f. Curitiba. Tese (Doutorado em Ciências Florestais - Área de Concentração Economia e Política Florestal). UFPR, Setor de Ciências Agrárias, Curso de Pós-Graduação em Engenharia Florestal, 2000.

SOUSA, Í. Z. G. de. Mercado varejista de madeira serrada de Rio Branco, estado do Acre, 2005-6. 65 f. Monografia (Bacharelado em Engenharia Florestal) UFAC, Departamento de Ciências Agrárias, Curso de Engenharia Florestal, 2007.

SPROULL, N. L. Handbook of research methods: a guide for practitioners in the social sciences. New Jersey: The Scarecrow Press, 1988. 404 p.

STEAD, R.; CURWEN, P.; LAWLER, K. Industrial economics: theory, applications and policy. London: McGraw-Hill Book Company Europe, 1996. 222 p.

STEELE, H. L.; VERA FILHO, F. M.; WELSH, R. S. Comercialização agrícolan. São Paulo: Atlas, 1971. 443 p. (Programa de Publicações Didáticas - Agência Norte-Americana para o Desenvolvimento Internacional-USAID).

VARIAN, H. R. Microeconomia: princípios básicos. 2. ed. Rio de Janeiro: Campus, 1997. 710 p. ZOBER, M. Administração mercadológica. Rio de Janeiro: Livros Técnicos e Científicos, 1971. 488 p. 